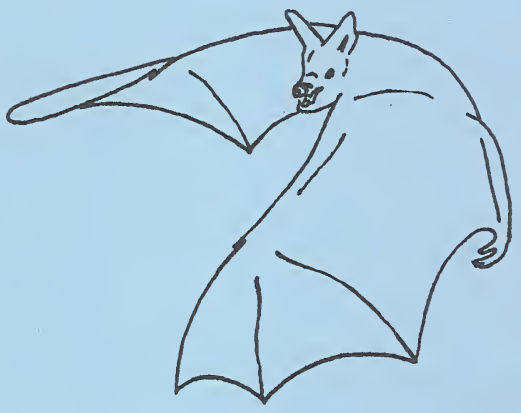

DEPARTMENT OF HEALTH AND ENVIRONMENTAL SCIENCES

ENVIRONMENTAL SERVICES BUREAU

JANUARY 1974

VECTOR CONTROL BULLETIN NUMBER 2 , 


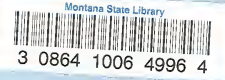


TABLE OF CONTENTS

Introduction. ...........................

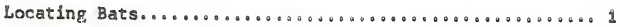

Control Methods.............................. 2

Physical Control.........................

Chemical Control.......................

Repellents.........................

Toxicants........................... 4

Bats and Disease..........................

Characters Used in Identification................6

Identification Keys.........................

Notes on the Biology of Montana Bats.................

Distribution of Species.........................

References........................................ 14 

Bats are considered beneficial because they consume large quantities of insects. Unfortunately, they are considered symbols of evil by some persons. Sometimes bats cause annoyance because of offensive odors or noises; sometimes fecal droppings deface buildings; and sometimes rabies infections cause concern in a community. For these reasons, control may be called for. A section on control methods (bat proofing, repellents or destruction) is included in this brochure.

A section on identification is also included. Identification of bat species is necessary for several reasons:

1. The biology of the species (i.e. the time young are born, the length of time until young learn to fly, and other varying habits and habitats) may dictate the timing or method of control.

2. To avoid the senseless killing of innocent and beneficial species (while the big brown bat, Eptesicus fuscus, has accounted for about $\frac{1}{2}$ of the rabies diagnoses in bats in Montana, some species have never been found rabid in the state). There is no reason for destruction of a colony of one species of bat in a building if a rabid bat of a solitary or tree-dwelling species was found in the area.

3. Some species are rare in Montana, e.g. the spotted bat, and deserve protection (8).

4. Identification will assist public officials in more adequately detemining what species of bats are most frequently involved in rabies.

Thirteen species of bats have been collected in Montana or adjacent to it. Another species collected adjacent to the state may possibly be found. All of these flying mammals in Montana belong to the family Vespertilionidae. Baby bats cannot be identified except by experts; juveniles (recognized by light colored cartilagenous finger joints) can be classified, with some difficulty, with the following key. Known distributions may also be of some assistance in making identifications.

The Department wishes to thank Dr.J.F. Bell of the Department of Health, Education and Welfare, Rocky Mountain Laboratory in Hamilton for his review and comments.

\section{LOCATING BATS}

Bats are most noticeable while foraging at or shortly after dusk. However, as a practical consideration, the roosting sites and/or harborage of the colonies may need to be located. In general, larger colonies are easier to locate. The presence of bats may be determined from their high pitched squeaking, rustling, odor, stains on buildings, or the accumulation of dropping (consisting mostly of insect exoskeleton remains) below roosting sites. However, rustling and twittering in chimneys, often attributed to bats, is often caused by nesting climney swifts (insect eating birds). The edges of entrances into buildings which are used by bats may have stained areas which are often quite conspicuous. One may also observe (as in the case of, e.g. Myotis lucifugus) fecal spatterings on the wall below entrances. A flashlight may have to be used to locate openings used by species which are late fliers. Other species emerge while it is still light enough to see. Most colonial bats become noisy an hour or two before leaving their roosts. Tree dwelling species conceal themselves among the foliage and may be very 
difficult to locate. Roosts of those living beneath the loose bark of trees or in crevices may also be hard to find. Sometimes groups of bats will stop and rest in unusual locations for only a day or two during migration or wandering.

CONTROL METHODS

In situations where control of bats is likely to be desired (i.e. in or near inhabited buildings) the first consideration and method of choice is to bat proof the site. Although repellents have only a temporary effect, some situations may call for their use. Bat proofing may have to be delayed or it may not be feasible to bat proof large buildings or open night roosting places such as porches. Extermination of a colony should be considered only as a last resort or possibly when rabies is present in a colony.

Methods of controlling bats may be geared to their habits and habits differ among species. Hence, the necessity for identification. Many species of bats will not tolerate disturbance and may desert a roost if molested.

\section{Physical Control}

Timing

Bat proofing is ideally and most simply accomplished during the season that bats are not occupying the site from which removal is desired. In Montana, this will most often be between Novembe $z$ and early March when bats have migrated out of the state or are hibernating in caves. The least desirable time to bat proof a building is between early June and mid-September. (Most young are born in June or July and do not leave the roost for about 6 weeks). If exclusion or strong repellents are used at this time, the young bats may starve to death and produce offensive odors or accumulate on the ground and attract the attention of flies, children or pets. Bats, even if not rabid, will bite if handled.

\section{Bat Proofing--Exclusion}

Bat colonies may be removed from a roost by closing all openings which are larger than $\frac{1}{4}$ inch. Hardware cloth on sheet metal may be nailed over larger openings; steel wool or fiberglass may be used to fill cracks and crevices. Roosts on the outside of buildings should aiso be eliminated if possible.

In all cases, bats should be outside the building when bat proofing is completed. When excluding bats while they are still present (when young bats have not yet been born or when young are foraging with adults):

1. Close all but a couple of the main entrances/exits.

2. Wait a few days until bats are used to using the remaining entrances/exits

3. Close the remaining openings when all bats have flown out in the evening.

The building should be checked for several nights to insure that closure has been complete. A repellent used in combination with the closure or in lieu of waiting will help assure that all bats capable of flying have departed. 
In most species, mothers retrieve thein young when they are placed on the ground below or near thoir noost. It is possible that young physically removed from maternity colonies will be taken to a tew roost if the old one has been bat proofed.

Trapping/Netting/Shooting

Again, rapping, netting on shooting adults during the active season is not recommended. Under some cincumstances, bats can be taken with dust shot, hand collected while wearing heary gloves, or, if confined, collected with a long handled net. These control methods may be practical where there are small colonies (as are characteristic of some species). Individuals netted or trapped could be released after completion of bat proofing. Simple displacement is not likely to be effective as some species have returned to their roost after being released over 500 miles away.

If there are only a few entrances for a colony, a cloth sleeve attached between the exit and a wire cage may be effective. Sometimes bats are reluctant to enter such a trap. Japanese mist nets may be effective at ensnaring some fast flying species, but. are not effective against slow cautious fliers. If bats are entangled in such a net for very long, removal may be difficult or the bat may be harmed. Nets strung across entrances to nearby caves or open buildings which are used as temporary night roosts will take some species of bats.

\section{Chemical Control}

\section{Repellents}

Bats are repelled by paradichlorobenzene and naphthalene (moth balls), bird repellents, rodent repelients, dog repellents and by the repellent formula noted below. Adults will often abandon their young if repellents are used while they are flightless. It is suggested that repellents not be used under those circumstances.

The use of repelients in the absence of bat proofing often has a temporary effect. Paradichlorobenzene and naphthalene which are used at 3 to $5 \mathrm{lbs}$. In the average sized attic, dissipate upon exposure to air. Bats (which have a strong homing instinct) may return in one or two weeks or, if not that season, then perhaps the next. Vapona strips have also been reported to repel bats. Naphthalene is the only product currently registered by the EPA for bar control.

The following formula (5) repels bats when painted or sprayed on surfaces upon which bats are known to rest (e.g. ceilinge, the upper parts of walls, and non-removable roosts). Depending upon tire species involved, one treatment may be effective for several months. CAUTION: The formula is irritating and should be mixed and used while wearing goggles, gioves, and protective clothing. Avoid prolonged breathing of vapors.

Thoroughly mix in order:

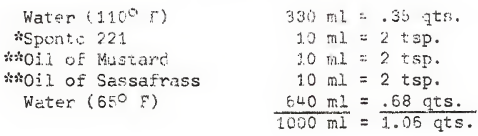

* Emulsifying Agent - Retziotf Chemical Corp., Box 45296, Houston, Texas th Arcmatic Oils - Magrus, Maijee and Feynard Inc., New York City 
At the time of this writing, EPA has indicated that no toxicants are currently registered for bat control. It should be recognized that a given site could be re-inhabited by bats in the future if only toxicants are used. Dead bats can cause odor if not removed. Again, killing bats is a last resort. "Perhaps an exception should be made if there is strong reason to suspect that rabies is circulating in a specific colony" (4). Excluding or repelling rabid bats could cause the virus to spread to other colonies, but this is not established.

Persons destroying bats sometimes take advantage of their habit of grooming themselves and (at least in some cases) each other when they return to the roost. In the past, $50 \%$ DDT wettable powder dusted or sprayed on entrances and roost areas was found to be effective. Bats removing the insecticide from their fur consume lethal amounts. Bats are about 20 times more sensitive to DDT in the spring (following depletion of their fat reserves by hibernation) than they are in the autumn. However, the Center for Disease Control, ceased to recommend the use of DDT several years ago. Since the DDT may act slowly, the danger of exposure of children and pets to diseased and dying bats could be greater if DDT were used than if no control were exercised.

Several anticoagulants found to be effective in controlling vampire bats in Latin America are chlorophacinone (RoZOL) ( 6 ) and diphenadione $(6,7)$. Although not yet registered, anticoagulatns mixed with dissolved petroleum jelly and applied to entrances and roosts might also be effective against the insect eating bats in Montana. However, anticoagulatns are also slow acting toxicants.

Fogging, misting on fumigating a building may be suitable under some conditions. This should be done only by a licensed professional. Application of a toxicant directly to bats may result in an almost "immediate" kill. Calcium cyanide (A-dust) has been reported to be effective in Caifornia (4). Other compounds such as fenthion (Baytex) rapidly exterminate a colony but are not registered for the purpose and parties using such compounds may come under the misuse provisions of the pesticide act.

\section{BATS AND DISEASE}

The part that bats play in the overall distribution of rabies and the manner in which it spreads among bats are not well understood. Murray (4) points out that there is no evidence of large die-offs of colonies in California and that infected individuals are found in a scattered pattern. More than sixty rabid bats were found in Montana between FY 1964 and 1973 (8). Many more no doubt have been rabid. In 1973, one bat that bit a child was confirmed as rabid.

Bats develop both the rurious and dumb or paralytic forms of rabies and occasionally attack man without provocation $(8)$. Swooping, darting flight while foraging is normal behavior but erratic flight with frequent landings, daytime exposure in the open and helpless flopping on the ground are common symptoms of rabies in bats. All bats will try to bite if handled; children should be warned not to pick them up. It is through attempts to handle sick individuals that most exposure to rabies from bats may be expected. Rabid bats are often found by dogs and cats which may then be exposed to bites. If an individual is bitten, immediate medical attention is called for. An unprovoked attack by a bat is ordinarily sufficient reason for anti-rabies treatment even if the bat is not captured. Bats which are apparently sick or those which have bitten people should be captured, if possible, and shipped in wet or dry ice to the 
Diagnostic Laboratory, Department of Livestock, Box 997, Bozeman, Montana, 59715. Shipment in dry ice is easier but it is not always available. If captured over the weekend, bats should be refrigerated and shipped Monday morning. Do not handle or attempt to capture bats without heavy gloves or forceps.

Rabies is usually transmitted by inoculation of the virus through the skin with infected saliva. Thus, bites account for most cases of rabies transmission. Entrance of the virus through scratches or open wounds and aerosol transmission in bat infested caves have been reported but much less commonly so.

Bat feces in the soil can produce favorable conditions for the growth of a fungus that causes histoplasmosis. This disease is caused by breathing the dust containing the fungus spores. Mild cases resemble influenza; in severe cases lesions in the lungs simulate the lesions of tuberculosis. Histoplasmosis is very uncommon in Montana. 
CHARACTERS USED 
(As Abstracted From Bats of America and A Guide to Montana Mammals)

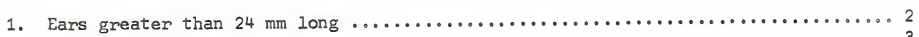

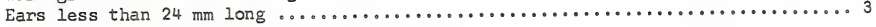

2. Fur black with 3 large white spots, one on each shoulder and one at base of tail ............................. maculatum Fur dark at base, tan to brown belly fur; with conspicuous club-shaped lumps on each side of muzzle Plecotus townsendii

3. Upper (dorsal) surface of interfemoral membrane well furred, at least on forward (anterior) half $\ldots \ldots \ldots \ldots \ldots \ldots \ldots \ldots \ldots . \ldots 4$ Dorsal surface of interfemoral membrane naked or

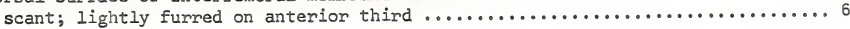

4. Fur black, with many silver-tipped hairs; forearms 37-44 mm, two upper incisors on each side (in part)... Lasionycteris noctivagans color various, not uniformly black; silver-tipped or not $\ldots \ldots \ldots \ldots \ldots \ldots \ldots . . .5$

5. Ears conspicuously black-edged with patches of yellowish hair inside; forearm $46-58 \mathrm{~mm}$ long; many white-tipped hairs give a frosted appearance ........... Lasiurus cinerus Ears not conspicuously black-edged, bare or scant haired inside; forearm 35-45 mm long (Occurrence uncertain)... Lasiurus borealis

6. Fur black, conspicuously silver-tipped (in part) ...... Lasionycteris noctivagans

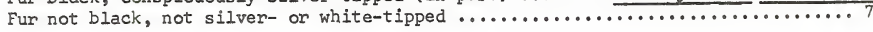

7. In a side view the first visable tooth behind upper canine about half as long as canine and in contact with it at base; forearm more than

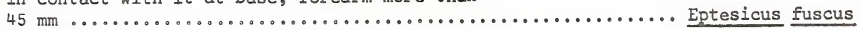

First tooth behind canine less than $1 / 3$ as long as canine or if $1 / 2$ as long separated from

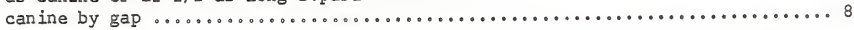

8. Conspicuous fringe of short, stiff hairs project back from free edge of interfemoral membrane;

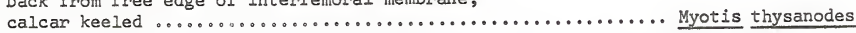
Conspicuous fringe of hairs on free edge of

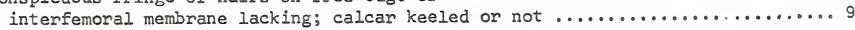

9. Ear longer than $16 \mathrm{~mm}$, extends more than $2 \mathrm{~mm}$

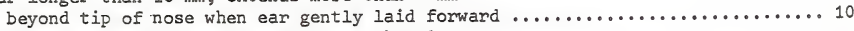
Ear shorter than $16 \mathrm{~mm}$, extends less than $2 \mathrm{~mm}$

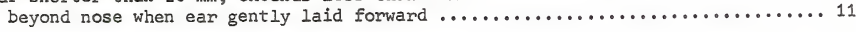

10. Ear black, usually longer than $17 \mathrm{~mm}(22-25 \mathrm{~mm}) \ldots \ldots \ldots \ldots \ldots$ Myotis evotis

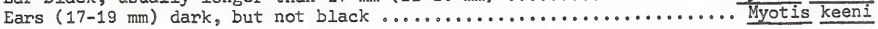

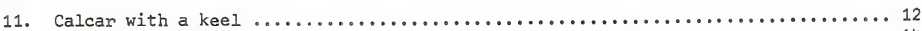

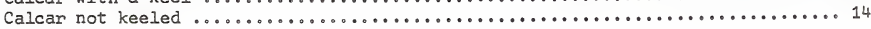


12. Foot over $8.5 \mathrm{~mm}$ long; forearm usually longer than

$35 \mathrm{~mm}$; anterior fourth of dorsal surface furred;

underwing furred to ellow and knee $\ldots \ldots \ldots \ldots \ldots \ldots \ldots \ldots \ldots$ Myotis volans

Foot shorter than $8.5 \mathrm{~mm}$, forearm usually shorter

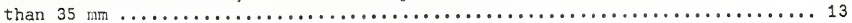

13. Frontal area of skull rising abruptly from the rostrum; dorsal fur dark with dull tips; ears

and wing membranes dark brown ............................. californicus

Skull. flattened, frontal area rises gently from

the rostrun; dorsal fur yellow to olive with

glossy tips; ears, wind membranes, and face fur black .......... Myotis leibii

14. Greatest length of skull usually not more than $14 \mathrm{~mm}$; fur usually with dull tips; ears and wing

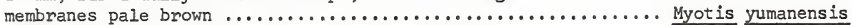

Skull usually longer than $14 \mathrm{~mm}$, fur longer and

usually with glossy tips; ears and wing membranes

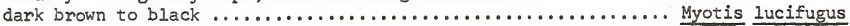




\section{(Principle Reference: Bats of America)}

Myotis lucifugus (little brown myotis; little brown bat)

The most common bat in Montana (3). Myotis lucifugus may form large summer nursing colonies in buildings (usually in a hot dark attic; occasionally beneath tar paper, siding or shingles). Colonies have been found under bridges and in caves; most often near open water. The species is known to hibernate in caves and mines in the east. Large hibernating colonies have not been located in Montana. Bats returning to the roost may make many passes at the entrance, defecating and splattering the wall under the opening. The little brown myotis has a strong homing instinct. Some have returned to the roost after being displaced several hundred miles.

In Vermont, the spring migration begins in early April and is completed by mid-May. Young are born during July in Montana. The mother will carry her single baby bat in flight attached to a nipple if disturbed but is thought to leave its young at the roost while feeding. Young bats fly outside the shelter at the age of about one month. Young are weaned in late August. Maternity colonies disperse, congregate in caves, and then depart for their summer range, returning to the caves later to hibernate. Myotis lucifugus colonies may contain some Myotis yumanensis, M. volans, M. californicus or Eptesicus fuscus.

Myotis yumanensis (Yuma myotis)

One of the more common bats in Montana west of the divide. This species is more closely associated with water than other bats. Nursery colonies are found in buildings, under bridges, and in caves and mines. Nursery colonies have been reported to be reduced in size after they have been disturbed. Single young are produced annually. It is usually found in mixed colonies with Myotis lucifugus. As in other Myot is species, males are usually found as solitary individuals or with males of other species. Bats migrate to nursery colonies in April and depart by the end of September.

Myotis keeni (Keen's myotis; Keen's bat)

Nothing is known of this species in Montana. Its occurrence is not confirmed. This bat has been most commonly found in mines and caves in the northern regions of the midwest and east. There are, however, records of Myotis keeni occurring in buildings. A nursing colony of thirteen individuals in a ban was reported. A British columbia race is a solitary species roosting in tree cavities and cliff crevices. Myotis keeni is usually found singly or in small nursing colonies. They commonly roost in caves at night during the summer. The species usually hangs singly, preferring tight cracks and holes. It has been found under tree bark, under shingles, and behind window shutters.

\section{Myotis evotis (long-eared myotis)}

Although widely distributed in the state, Myotis evotis is not overly common. The preferred habitat is among coniferous forests. In summer, specimens are often found in cabins and sheds where maternity colonies are formed. The species often uses caves at night but does not usually live in them. The single young are probably born in early to mid-July in Montana, although data is lacking. 
This species forms large colonies of perhaps several hundred. Myotis thysanodes roosts day and $n i g h t$ in caves, rock crevices, and buildings. Droppings on the floor may indicate the site of a night roost unoccupied by day. They have been successfully netted in open doors and windows in barns. Matemity colonies break up in the fall but nothing is known of their movements.

Myotis volans (long-legged myotis)

Although widely distributed in the western half of the state, this species is not common. Myotis volans "occurs at higher elevations than other Montana bats" ( 3 ). This species is usually found in small separate colonies or in larger colonies with Myotis Iucifugus. Occasionally it forms large nursing colonies in buildings, rock crevices, and, most commonly, trees. The long-legged myotis frequently enters caves and mines at night. The date at which young are born varies with altitude and latitude, but occurs earlier than that of most species. Collection of lactating females with mist nets appears to indicate that young are left in the colony while the mother feeds. Colonies depart in the fall but nothing is known of their movements.

\section{Myotis californicus (California myotis)}

M. californicus is a lowland species which is found in small sumer colonies in restricted locations (the Bitterroot and Flathead Valleys) or as individuals in Myotis lucifugus colonies. $M_{0}$ califomicus has a strong tendency to use man-made open structures near feeding areas as night roosts. Tiny droppings may be found below these spots. They may be taken by placing a mist net over the opening. Summer daytime roosts include a variety of crevice-like places (under loose bark, in rock crevices, in buildings, under bridges or sign boards). This species appears to move from site to site without establishing a habitual hiding place, except when the small matemity colonies are formed. Myotis californicus hibernates in mines in other states.

Myotis leibii (small-footed myotis; least brown bat)

This species is distributed over the entire state. It at least occasionally inhabits buildings. Small maternity colonies have been found beneath wallpaper, in barns, in out-buildings, and under tree bark. Buildings and caves are used for night roosts. These bats are slow fliers and may avoid set mist nets. Myotis leibii is a very cold hardy species. It has been found to leave its cold, drafty hibernation sites near the entrance to caves and mines by March in New York. It did not move into caves for hibernation until mid-November in Vermont. Thus, the optimum time for bat proofing may begin later in the winter than with other species and end earlier in the spring. This species has been found hibernating in neighboring states and in Canada. Its winter range may overlap its summer range in Montana.

Lasionycteris noctivagans (silver-haired bat)

This species occasionally forms nursery colonies but adults are usually found singly or in small groups. It appears to be restricted to coniferous forests throughout Montana in the summer. It migrates north in the spring to breed and south in the fall to hibernate. Since typical daytime roosts are behind the loose bark of trees, roosting sites are seldom found. In noctivagans may temporarily appear in open sheds, buildings or piles of lumber, etc. during migration. 
Eptesicus fuscus favors buildings as roosting sites, forming colonies in attics, barns etc. but may be found under bridges, etc. Stains left by bats, as on louvers in a church belfry, may be conspicious. Females return to their young after feeding; males may rest on night roosts such as porches or in garages with open doors. The big brown bat probably migrates out of Montana to hibemate in caves, but data is lacking( 3$)$. This species, however, has been found to hibernate in buildings in Maine and Minnesota. In British Columbia and Saskatchewan, it is also known to winter in mines and caves. If disturbed while hanging from a chimney or the rafters of an attic, some retreat to inaccessible crevices, some move to nearby roosts. Temperature in excess of $95^{\circ} \mathrm{F}$ causes them to move or seek cooler parts of the building. Heat spells may lead to detection of squeaks in the walls; some (especially young bats) may crawl out around cracks in a fireplace. The date that young are born varies with latitude. In North Dakota (and probably in Montana) the female gives birth to a single young in late June or early July. Young are left at the roost while the mother feeds. In some areas nursery colonies abandon roosts when the young are weaned; in others they leave only when cold weather arrives. The homing instinct is very storng, some individuals returning to the roost from 450 miles away. Eptesicus fuscus sometimes shares its roosts with Myotis yumanensis and Myot is lucifugus.

Lasiurus cinereus (Hoary bat)

The hoary bat is the largest bat in Montana. During summer, this species roosts by day in the foliage of trees. It almost never enters houses. This bat is seldom encountered except by those who recognize its characteristic swift and direct flight. Two young are born annually. A female and her young may be found on the ground if flightless young should fall from their daytime roost. The female cannot fly with the two young. This species performs long seasonal migrations; north in the spring, south in the fall.

Euderma maculatum (spotted bat)

This species is extremely rare in Montana as it is throughout the United States. Evidence indicates that this species roosts in cracks and crevices of high cliffs and canyons. The only specimen taken in Montana was collected as it flew in an open window in Billings ( 3 ). Little is known of its biology or habits.

Plecotus townsendii (western big-eared bat; Townsend's big eared bat)

Plecotus townsendil, which is widely distributed in southern, central and western Montana, is found in a variety of situations. It often has summer daytime roosts in caves but also frequently establishes small nursery colonies in attics. Open buildings are used as night roosts. Males are usually solitary. Plecotus townsendii does not enter cracks or crevices, but hangs from open ceilings. (It would not be necessary to fill cracks when bat proofing for this species). Since this species takes late feeding flights, they are not often seen emerging from their harborage. As they are cautious fliers, they are more difficult to trap with a mist net than are many other species. Banding of the young while adults were feeding has caused a nursery colony to move. Hence, disturbing a colony may encourage them to select another roost. Young leave the roost at six weeks of age and are weaned at the age of about two months. Colonies disperse at about this time (probably late August). Plecotus townsendii is known to hibernate in caves (such as the Lewis and Clark Caverns where large numbers occur). 
Lasiurus borealis (red bat)

This tree-dwelling bat has not been encountered in the state but has been found near the eastern border. Its winter range is in the southern half of the United States where this species joins others in caves. 


\section{Species}

1. Myotis lucifugus

2. Myotis yumanensis

3. Myotis evotis

4. Myotis thysanodes

5. Myotis volans

6. Myotis californicus

7. Myotis leibii

8. Myot is keeni

9. Lasionycteris noctivagans

10. Eptesicus fuscus

11. Lasiurus cinereus

12. Euderma maculatum

13. Plecotus townsendii

14. Lasiurus borealis

\section{Distribution (County Records ${ }^{1}$ )}

Widely distributed; Counties: Powder River

West of Continental Divide; Counties:

Flathead, Lake, Missoula, Ravalli

Widely distributed; Counties: Fergus, Flathead, Glacier Park, Jefferson, Lake, Meagher, Missoula, Powder River, Ravalli, Sanders

Southwestern Montana; Counties: Jefferson, Missoula, Ravalli

Fairly widely distributed, western half of state; Counties: Fergus, Flathead, Granite, Lake, Missoula, Ravalli

Probably just in Bitterroot and Flathead Valleys; Counties: Flathead, Ravalli

Widely distributed; Counties: Custer, Missoula, Powder River, Ravalli, Sweet Grass

Occurrence uncertain, no county records; mapped to include the most eastern counties of Montana from a record in adjacent Buford, North Dakota

Probably widely distributed; has been mapped to include entire state ${ }^{2}$

Widely distributed; has been mapped to include entire state

Widely distributed; has been mapped to include entire state ${ }^{2}$

Mapped in south-central Montana; ${ }^{2}$ Counties: Yellowstone

Widely distributed. Has been mapped to include southem counties of Montana. ${ }^{2}$

Counties: Beaverhead, Choteau, Fergus, Flathead, Lake, Jefferson, Madison, Missoula, Powder River, Ravalli, Sanders, Yellowstone

Has been mapped up to but not including the eastern counties of Montana. ${ }^{2}$ No county records 
1. Hoffman, R. S., Pattie, D. L., and Bell, J. F. (1969), The Distribution of Some Mammals in Montana, II. Bats, J. Mammalogy, 50(4): 737-741.

2. Barbour, R. W., and Davis, W. H. (1969), Bats of America, University of Kentucky Press, $286 \mathrm{pp}$.

3. Hoffman, R. S., and Pattie, D. L. (1968), A Guide to Montana Mammals, Identification, Habit, Distribution and Abundance, pp. 12-15.

4. Murray, K. F. (1969), Community Pest and Related Vector Control, Chapter 15, Bats in California, pp. 181-185. Brooks, J. E., and Peck, T. D., Editors.

5. CDC - Veterinary Public Health Notes, February 1967 (as revised).

6. Linhart, S. B., Crespo, R. F., and Mitchell, G. C. (1972), Control of Vampire Bats by Topical Application of an Anticoagulant, Chlorophacinone, Boletin De La Osp (English Ed.), V1 (2):31-38.

7. Thompson, R. D., Mitchell, G. C., and Burns, R. J. (1972), Vampire Bat Control by Systemic Treatment of Livestock with an Anticoagulant. Science 177:806-807.

8. Bell, F., (1973) Personal communication. 

